\title{
INFLUENCE OF MATERNAL MUSCLE ACTIVITY ON LABOR AND PREGNANCY OUTCOME
}

\author{
Ghada A. Fouad ${ }^{(1)}$; Moustafa H. Ragab ${ }^{(2)}$ \\ and Ibrahim R. ELsawy ${ }^{(3)}$ \\ 1) Ossem Central Hospital 2) Institute of Environmental Studies and \\ Research Ain shams University 3) Faculty of Medicine, Azhar University
}

\begin{abstract}
Physical activity in all stages of life maintains and improves cardio respiratory fitness, reduces the risk of obesity and associated comorbidities and results in greater longevity. Physical activity in pregnancy has minimal risks and has been shown to benefit most women, although some modifications to exercise routines may be necessary because of normal anatomic, physiologic changes and fetal requirements. So, this is a hospital longitudinal study extended from January 2015 to August 2015 on 100 female subjects all are volunteers seen in first stage of labor of full-term pregnancy, 63 subjects are performing relatively maternal muscle activity and 37 female subjects are performing strenuous muscle activity are included in the study. Then all participants had their labor and new born outcomes evaluated through consultation of medical records. There were statistically significant differences between the two groups regarding duration of $2^{\text {nd }}$ stage of labour, type of labour, Apgar score and placental separation whether early or late, but no significant difference between the two groups regarding complete or partial separation of placenta.

Conclusion: Relatively maternal muscle activity of women is healthy and beneficial and is associated with less disturbance of pregnancy and labor outcomes, while on the other hand strenuous muscle activity is harmful being associated with many pregnancy complications such as prolonged second and third stage of labor, lower odds ratio of eutocic birth, statistically significant
\end{abstract}


decrease in first and fifth minute APGAR score after labor, increased rate of Cesarean section and difficult vaginal delivery.

Recommendation: All obstetricians, family medicine doctors and health care providers trained for advice and intervention to modify pregnant physical activity to adapt her life circumstances and her pregnancy issues. Further studies to examine association between maternal muscle activity and pregnancy and labor outcomes.

Keywords: Relatively maternal physical activity - pregnancy - labour outcome.

\section{INTRODUCTION}

The present study was conducted to investigate the effect of maternal muscle activity on labour and pregnancy outcome. Pregnancy is important because maternal health and well-being directly affects another person's life. The well-being of people who have prospects in life depends upon healthy women and mothers (Sadeghi et al., 2018). A healthy lifestyle that incorporates ordered levels of physical activity in the course of pregnancy may contribute to progressed pregnancy outcomes. In normal pregnancy, there is no need for women to give up their current life activities. Every woman should take care of her organism through being active and maintaining physical and mental health, good posture and keeping proper body weight. There is no doubt that individually tailored physical activity during pregnancy is essential (Jackson et al., 2015). Studies conducted in recent decades have showed that women comprise half the world's population, and perform two thirds of productive work worldwide (Khojasten et al., 2016). Physically demanding work such as heavy lifting, excessive 
Journal of Environmental Sciences (JES)

Institute of Environmental Studies and Research, Ain Shams University

Fouad, Ghada et al.

repetition, awkward postures, and prolonged periods of sitting or standing is associated with low back pain and musculoskeletal disorders in the pregnant women (Salihu et al., 2012). Pregnant women are at an increased risk of falls because of joint laxity and a shifting center of gravity. Thus, consideration of accommodations for some pregnant women whose work may be associated with an increased risk of falls may be warranted with advancing gestational age (Jackson et al., 2015). Multiple studies confirm that it is generally safe for a woman with an uncomplicated pregnancy to work throughout most of the pregnancy without adverse effects for the woman or her infant (van Beukering et al., 2014). However, Physical activities at work might adversely impact on pregnancy outcomes such as preterm delivery and low birth weight (Bonzini et al., 2006; Niedhammer, O’Mahony, Daly, Morrison, \& Kelleher, 2009; Palmer, 2013; Naseriasl et al., 2014). Working more than 40 hours per week was associated with increased risk on pregnancy and labor, but the association was not significant when limited to higher quality studies. No increased risk was found for mixed shift work, lifting more than $100 \mathrm{~kg} / \mathrm{day}$, or standing more than 6 hours per day. However, a large retrospective cohort study of occupational lifting showed elevated risk of miscarriage associated with extensive lifting (Juhl et al., 2013).An observational study to detect effects of recommended levels of physical activity on pregnancy outcomes results in active women have better aerobic fitness as compared to inactive women. The risk of operative delivery is lower in active women compared to 
Journal of Environmental Sciences (JES)

Institute of Environmental Studies and Research, Ain Shams University

Fouad, Ghada et al.

inactive when controlled for birth weight, maternal weight gain and parity. Further studies are required to confirm the association between physical activity and pregnancy outcomes.(Mezler ,2010) Thus, for the many shortand long-term health benefits of physical activity, it is important to study physical activity behavior among pregnant women. Pregnancy is a life changing event that can initiate an adverse change in physical activity.

\section{SUBJECTS AND METHODS}

This is a hospital longitudinal study extended from January 2015 to August 2015 on 100 female pregnant subjects all are volunteers often taking their agreement as they are coming in labor in first stage with uterine contraction and cervical dilatation. All volunteers undergone history taking by direct questionnaire (Kaiser physical activity Survey) This is a questionnaire based on the ( Baecke, et al., 1982 ) physical activity research and was specifically projected for the assessment of physical activity in women. It is instrument that evaluates the multiple domains of physical activity (domestic activity/caregiver, occupational, active life and sports/exercises) and its objective is to measure the types of physical activity performed by women which provides an encompassing assessment of each activity domain, and can be more useful for studies in which physical activity is the primary outcome. Some questions have been added and some are omitted to fulfill our volunteer's intelligence with the following inclusion and exclusion criteria. 


\section{Inclusion criteria:}

The study subjects were drawn from pregnant women being in the child bearing period having a singleton uncomplicated gestation coming to the hospital in $1^{\text {st }}$ stage of labor.

\section{Exclusion criteria:}

- Maternal causes: Including thyroid disease, heart diseases, restrictive lung disease, cervical incompetence, maternal muscle disease such as poliomyelitis and myasthenia gravis, risk of preterm birth, second or third persistent bleeding, severe anemia, preeclampsia or pregnancy induced hypertension and placenta Previa.

- Fetal causes: Interfere with normal labor such as hydrocephalus and to exclude malpresentation such as breech, shoulder and face presentation.

\section{History taking includes:}

- Personal history: name to be Familial with the patient.

- Type of work in 3rd trimester to assess muscle exercise performed indoor or outdoor and to analyze the kinds of muscle activity.

\section{A-Type of work:}

1) Inside home, if yes:

- There are home utilities such as vacuum, washing machine and dishwasher.

- Have a servant 
2) Outside home, if yes:

- Shift work, inconvenient work hours, irregular work hours or long working hours.

- Work exposure (prolonged bending, twisting or standing)

- Use a Car.

\section{$\underline{B \text { - Exercise perform stress }}$}

1) Walking (how far the distance to work, school of kids and any shores.

2) Climbing stairs (how many floors)

3) Carrying water container, gas container or heavy loads.

4) Attending gym or no.

\section{C-General Examination:}

- BP (blood pressure) to rule out pre -eclampsia - eclampsia \& persistent and hypertension with pregnancy.

- For BMI (body mass index) to exclude contributing factor for weak pelvic and /or abdominal muscles.

- BMI below 20 (underweight)

- BMI within 20- 25 (normal range)

- BMI 25 - 30 (over weight)

- BMI over 30 (obese)

\section{D-Vaginal examination to rule out:}

1) Intrapartum hemorrhage

2) Uterine contractions.

3) ROM (rupture of membranes). 
Journal of Environmental Sciences (JES)

Institute of Environmental Studies and Research, Ain Shams University

Fouad, Ghada et al.

4) Attitude, lie presentation, position, engagement, station and progress of labor or arrested.

5) Follow up stages of labor.

- 1st stage of labor begins with full cervical dilation to $10 \mathrm{~cm}$ (Hutchison,2019) when contractions become strong \& regularly spaced at approximately 3 to 5 minutes apart (Liao, 2005)

- The presenting fetal part begins engagement into pelvis and cervical effacement when completely thinned out and no length is left this is referred to 100 percent effacement (Liao, 2005)

- Station of the fetus is defined relative to its position in the maternal pelvis. When bony fetal presenting part is aligned with maternal ischial spine the fetus is 0 station. Proximal to the ischial spines are stations (-1) centimeters to $(-5)$ centimeters, and distal to the ischial spines +1 to +5 centimeters stations (Hutchison, 2019)

- Dilatation rate of 1.2 to 1.5 centimeters per hour is the normal in active phase. Multipara tend to demonstrate more rapid cervical dilatation (Hutchison, 2019)

- The absence of cervical changes for greater than 4 hours in the presence of adequate contractions on six hours with inadequate contractions ( less than 3 contractions/10min ) are considered arrest of labor and may warrant clinical intervention (zhang et al, 2010). 
Journal of Environmental Sciences (JES)

Institute of Environmental Studies and Research, Ain Shams University

Fouad, Ghada et al.

- Second stage of labor commences with complete cervical dilation to 10 centimeters and ends with the delivery of the neonate. The fetus passes through the birth canal via 7 movements known as cardinal movements. These include engagement, decent, flexion, internal rotation, extension, external rotation and expulsion (Liao, 2005)

6) Mode of delivery: Normal easy delivery, normal delivery with episiotomy or cesarean section.

7) Placental separation: Also known as third stage of labor. Whether early or late, partial or complete.

Spontaneous expulsion of the placenta typically takes between 5 to 30 minutes. A delivery time of greater than 30 minutes is associated with higher risk of post hemorrhage and may be an indication for manual removal or others intervention (Hutchison, 2019)

8) Apgar score of the baby. The Apgar score, a tool used to assess well-being at 1 and 5 minutes after birth, incorporates five elements: respiratory effort, heart rate, reflex irritability, muscle tone, and color. In the preterm infant, the Apgar score is directly related to birth weight and gestational age. Among premature infants, Apgar scores are significantly higher at 1 and 5 minutes in females. In addition, male premature infants frequently require more vigorous resuscitation. Higher Apgar scores in the preterm female infant may be related to higher catecholamine levels found in female infants at birth, resulting in a more normal response and improved cardiovascular stability. (Rosen and Bateman, 2010). 
Table (1): Apgar score:

\begin{tabular}{|c|c|c|c|}
\hline Indicator & 0 points & 1 point & 2 points \\
\hline \hline Appearance & Blue, Pale & Pink body, Blue extremities & Pink \\
\hline Pulse & Absent & below 100 bpm & over 100 bpm \\
\hline Grimace & Floppy & minimal response to stimulation & $\begin{array}{c}\text { prompt response to } \\
\text { stimulation }\end{array}$ \\
\hline Activity & Absent & Flexed arms and legs & Active \\
\hline Respiration & Absent & Slow and irregular & Vigorous cry \\
\hline
\end{tabular}

\section{RESULTS}

Table (2): BMI categories of the whole study population $(n=100)$.

\begin{tabular}{|c|c|}
\hline BMI (kg/m2) category & No. $(\%)$ \\
\hline \hline Under Weight $(<20)$ & $3(3 \%)$ \\
\hline Normal Range $(20-25)$ & $54(54 \%)$ \\
\hline Overweight $(25-30)$ & $38(38 \%)$ \\
\hline Obese $(>30)$ & $5(5 \%)$ \\
\hline
\end{tabular}

As shown in table (2) regarding body mass index (BMI) categories of whole study population $(n=100) 54 \%$ subjects of participants had a normal range of BMI (20-25) while $38 \%$ of participants was fallen in category BMI (25-35) which is considered overweight, while only $3 \%$ are underweight $(<20)$ and $5 \%$ are obese. As a result of this study we cannot consider BMI a contributing factor affect the pregnancy and delivery outcome because $92 \%$ of participants are fallen between the two groups BMI (20-25) and BMI (25$35)$, while only $3 \%$ were underweight BMI $(<20)$ and $5 \%$ were obese BMI ( >35) which means no significant difference of the BMI of participants in general. 
Table (3): Type and character of work among the whole study population $(n=100)$.

\begin{tabular}{|c|c|}
\hline Data related to maternal work & No. (\%) \\
\hline \multicolumn{2}{|c|}{ Type of work } \\
\hline Inside home & $63(63 \%)$ \\
\hline Home utilities usage & $54(54 \%)$ \\
\hline Have a Servant & $9(9 \%)$ \\
\hline Outside home & $37(37 \%)$ \\
\hline Shift work & $9(9 \%)$ \\
\hline Inconvenient work hours & $11(11 \%)$ \\
\hline Irregular work hours & $2(2 \%)$ \\
\hline long working hours & $15(15 \%)$ \\
\hline Work exposure & $37(37 \%)$ \\
\hline Prolonged bending & $20(20 \%)$ \\
\hline Twisting or standing & $17(17 \%)$ \\
\hline \multicolumn{2}{|c|}{ Work activity } \\
\hline Maternal muscle activity & $100(100 \%)$ \\
\hline Relatively & $63(63 \%)$ \\
\hline Strenuous & $37(37 \%)$ \\
\hline \multicolumn{2}{|c|}{ Exercise perform stress } \\
\hline \multicolumn{2}{|l|}{ Walking } \\
\hline Short distance $<1 \mathrm{~km}$ & $53(53 \%)$ \\
\hline Long distance $>1 \mathrm{~km}$ & $31(31 \%)$ \\
\hline Have a car & $16(16 \%)$ \\
\hline \multicolumn{2}{|l|}{ Climbing stairs } \\
\hline Low floors (1-2 floors) & $74(74 \%)$ \\
\hline High floors ( $\geq 3$ floors $)$ & $26(26 \%)$ \\
\hline Carrying heavy loads & $40(40 \%)$ \\
\hline Attending GYM & $5(5 \%)$ \\
\hline
\end{tabular}


Table (3) shows type and character of work among the whole study population $(n=100)$. Also showing inside home utilities usage by participants which counts (54\%) also those who have servants count (9\%).

Regarding work outside home whether it is shift work, inconvenient work hours, irregular work hours or long work hours participants records $9 \%$, $11 \%, 2 \%$, and $15 \%$ respectively.

Also work exposure whether it is prolonged bending or twisting and standing participants records $20 \%, 17 \%$ respectively.

Also exercise performing stress included in this table showing different types of daily activities like walking, climbing, carrying heavy loads and attending gym.

Accordingly maternal muscle activity can be divided as relatively maternal muscle activity counted $37 \%$ of whole participants and strenuous maternal muscle activity which counted $63 \%$ of whole study population $(\mathrm{n}=100)$.

Table (4): Mode of delivery ( $\mathrm{n}=100)$.

\begin{tabular}{|l|l|}
\hline \multicolumn{1}{|c|}{ Mode of delivery } & No. (\%) \\
\hline \hline Normal easy delivery & $52(52 \%)$ \\
\hline Normal delivery with episiotomy & $30(30 \%)$ \\
\hline Cesarean section & $18(18 \%)$ \\
\hline
\end{tabular}

As shown in table (4) regarding the mode of delivery which means pregnancy outcome as a result of this study the number of subjects that have been recorded normal easy delivery are $52(n=25)$ out of 100 subjects have 
been participated in this study $(52 \%)$ while number of subjects that recorded normal delivery with augmentation and episiotomy are $30(n=30)$ out of 100 subjects $(30 \%)$ but rate of Cesarean section was only 18 subjects $(18 \%)$, so in this study we can notice that the physical activity in general does not increase the rate of c-section as delivery outcome.

Table (5): Association between maternal muscle activity and 2nd stage of labor plus mode of delivery.

\begin{tabular}{|c|c|c|c|c|}
\hline $2^{\text {nd }}$ stage labor & $\begin{array}{l}\text { Relatively } \\
\text { maternal } \\
\text { muscle } \\
\text { activity }\end{array}$ & $\begin{array}{l}\text { Strenuous } \\
\text { maternal } \\
\text { muscle } \\
\text { activity }\end{array}$ & \multirow[t]{2}{*}{$\begin{array}{c}\text { Chi- } \\
\text { square test }\end{array}$} & \multirow[t]{2}{*}{$\begin{array}{l}\text { P-value } \\
\text { (Sig.) }\end{array}$} \\
\hline Number & 63 & 37 & & \\
\hline $\begin{array}{l}\text { Normal without } \\
\text { augmentation and easy } \\
\text { vaginal delivery }\end{array}$ & $45(71.4 \%)$ & 7 (18.9\%) & \multirow[t]{3}{*}{26.346} & \multirow[t]{3}{*}{$\begin{array}{c}<0.001 \\
(\mathrm{HS})\end{array}$} \\
\hline $\begin{array}{l}\text { Prolonged with } \\
\text { augmentation and vaginal } \\
\text { delivery with episiotomy }\end{array}$ & $10(15.9 \%)$ & $20(54.1 \%)$ & & \\
\hline $\begin{array}{l}\text { Arrest followed by } \\
\text { caesarian section }\end{array}$ & $8(12.7 \%)$ & $10(27 \%)$ & & \\
\hline
\end{tabular}

$p<0.05$ is significant. Sig.: significance.

Table (5) of association between maternal muscle activity and $2^{\text {nd }}$ stage of labor plus mode of delivery showing a significant difference between both groups of relatively maternal activity and strenuous maternal activity, regarding the $2^{\text {nd }}$ stage of labor:

- Regarding normal easy delivery, $1^{\text {st }}$ group of relatively maternal muscle activity recorded $45(71.4 \%)$ while $2^{\text {nd }}$ group of strenuous maternal muscle activity recorded 7 (18.9\%). 
- Regarding prolonged $2^{\text {nd }}$ stage delivery with augmentation ended with vaginal delivery after episiotomy relatively group recorded 10 (15.9\%) while strenuous group record $20(54.1 \%)$.

- Regarding arrest of labor ended by $\mathrm{C}$-section relatively group recorded $8(12.7 \%)$ while strenuous group recorded $10(72 \%)$. P Value $<0.001$ (HS) highly significant.

Table (6): Association between maternal muscle activity and placental separation timing.

\begin{tabular}{|c|c|c|c|c|}
\hline $\begin{array}{c}\text { Maternal activity } \\
\text { Placental }\end{array}$ & $\begin{array}{c}\text { Relatively } \\
\text { maternal muscle } \\
\text { activity }\end{array}$ & $\begin{array}{c}\text { Strenuous } \\
\text { maternal } \\
\text { muscle activity }\end{array}$ & $\begin{array}{c}\text { Chi- } \\
\text { square test }\end{array}$ & $\begin{array}{c}\text { P-value } \\
\text { (Sig.) }\end{array}$ \\
\cline { 1 - 3 } Number & $\mathbf{6 3}$ & $\mathbf{3 7}$ & \\
\hline Early & $49(77.8 \%)$ & $20(54.1 \%)$ & \multirow{2}{*}{6.133} & \multirow{2}{*}{$\begin{array}{c}0.013 \\
(\mathrm{~S})\end{array}$} \\
\hline Late & $14(22.2 \%)$ & $17(45.9 \%)$ & \\
\hline
\end{tabular}

$\mathrm{p}<0.05$ is significant. Sig.: significance.

Table (6) of association between maternal muscle activity and placental separation timing showing significant difference between both groups (relatively and strenuous) regarding placental separation timing.

- Relatively muscle activity group recorded 49 out of $63(77.8 \%)$ with early placental separation versus 20 out of $37(54.1 \%)$ from strenuous muscle activity group, while 14 out of $63(22.2 \%)$ of relatively group recorded late separation of placenta versus 17 out of $3(45.9 \%)$ with the same factor. P Value (0.013) (S) significant. 
Table (7): Association between maternal muscle activity and placental separation.

\begin{tabular}{|c|c|c|c|c|}
\hline Maternal activity & $\begin{array}{c}\text { Relatively } \\
\text { maternal } \\
\text { muscle } \\
\text { activity }\end{array}$ & $\begin{array}{c}\text { Strenuous } \\
\text { maternal } \\
\text { muscle } \\
\text { activity }\end{array}$ & $\begin{array}{c}\text { Chi-square } \\
\text { test }\end{array}$ & $\begin{array}{c}\text { P-value } \\
\text { (Sig.) }\end{array}$ \\
\cline { 1 - 3 } Number & $\mathbf{6 3}$ & $\mathbf{3 7}$ & & \\
\hline \hline Complete & $52(82.5 \%)$ & $27(73 \%)$ & 1.286 & 0.257 \\
Partial & $11(17.5 \%)$ & $10(27 \%)$ & & $(\mathrm{NS})$ \\
\hline
\end{tabular}

$\mathrm{p}<0.05$ is significant.

Sig.: significance.

Table (7) of association between maternal muscle activity and placental separation whether complete or partial has shown no significant difference between both groups (relatively and strenuous).

- Relatively group recorded 52 out of $63(82.5 \%)$ with complete separation compared to strenuous group that recorded 27 out of 37 (73\%).

- Relatively group recorded 11 out of $63(17.5 \%)$ with partial separation compared to strenuous group that recorded 10 out of $37(27 \%)$.

$\mathrm{P}$ value (0.257) (NS) non-significant. 
Table (9): Association between maternal muscle activity and APGAR score.

\begin{tabular}{|c|c|c|c|c|}
\hline APGAR score & $\begin{array}{l}\text { Relatively } \\
\text { maternal } \\
\text { muscle } \\
\text { activity } \\
\end{array}$ & $\begin{array}{c}\text { Strenuous } \\
\text { maternal } \\
\text { muscle } \\
\text { activity } \\
\end{array}$ & $\begin{array}{c}\text { Chi- } \\
\text { square test }\end{array}$ & $\begin{array}{l}\text { P-value } \\
\text { (Sig.) }\end{array}$ \\
\hline Number & 63 & 37 & & \\
\hline $\begin{array}{l}\text { Severely depressed } \\
(0-3) \text { Points }\end{array}$ & $3(4.8 \%)$ & $2(5.4 \%)$ & \multirow[t]{3}{*}{19.533} & \multirow[t]{3}{*}{$\begin{array}{c}<0.001 \\
(\mathrm{HS})\end{array}$} \\
\hline $\begin{array}{l}\text { Moderately depressed } \\
\text { (4-6) Points }\end{array}$ & $15(23.8 \%)$ & $25(67.6 \%)$ & & \\
\hline $\begin{array}{l}\text { Excellent Condition } \\
\text { (7-10) Points }\end{array}$ & $45(71.4 \%)$ & $10(27 \%)$ & & \\
\hline
\end{tabular}

$\mathrm{p}<0.05$ is significant.

Sig.: significance.

Table (8) of association between maternal muscle activity and APGAR score of the baby. There is a significant difference between both groups regarding APGAR scoring system.

- Relatively group showed 3 out of $63(4.8 \%)$ with severely depressed babies versus 2 out of $37(5.4 \%)$ of strenuous group severely depressed babies.

- Relatively group showed 15 out of 63 (23.8\%) of moderately depressed babies compared with 25 out of 37 (67.6\%) of strenuous group.

- Relatively group showed 45 out of 63 (71.4\%) with excellent condition babies compared to 10 out of $37(27 \%)$ of strenuous group.

$\mathrm{P}$ Value $<0$.001 (HS) highly significant. 
Journal of Environmental Sciences (JES)

Institute of Environmental Studies and Research, Ain Shams University

Fouad, Ghada et al.

\section{DISCUSSION}

The present study was designed to investigate effect of maternal muscle activity on pregnancy and labor outcome, on fetal health and fetal wellbeing, it included 100 women coming in $1^{\text {st }}$ stage of labor who were subdivided in two groups according to their degree of physical activity, the first group with relatively muscle activity (63 subjects) and the second group included subjects with strenuous maternal muscle activity ( 37 subjects). Results of the present study added additional evidence in the effect of degree of maternal physical activity on pregnancy outcome, mode of delivery and APGAR score ( condition of new born after delivery), it showed that relatively maternal muscle activity were associated with less disturbance of fetal wellbeing and subsequently decreased pregnancy complications and better pregnancy outcome. From January (2015) to August (2015), A 100 healthy female subjects all are volunteers participated in hospital longitudinal study with inclusion and exclusion criteria have been determined. As shown in table (2) regarding body mass index (BMI) categories of whole study population $(\mathrm{n}=100) 54 \%$ subjects of participants had a normal range of BMI (20-25) while $38 \%$ of participants was fallen in category BMI (25-35) which is considered overweight, while only $3 \%$ are underweight $(<20)$ and $5 \%$ are obese. As a result of this study we cannot consider BMI a contributing factor affect the pregnancy and delivery outcome because $92 \%$ of participants are fallen between the two groups BMI (20-25) and BMI (25-35), while only $3 \%$ were underweight BMI $(<20)$ and $5 \%$ were obese BMI $(>35)$ which means 
Journal of Environmental Sciences (JES)

Institute of Environmental Studies and Research, Ain Shams University

Fouad, Ghada et al.

no significant difference of the BMI of participants in general. Table (3) shows type and character of work among the whole study population $(n=100)$. Also showing inside home utilities usage by participants which counts (54\%) also those who have servants count $(9 \%)$.

Regarding work outside home whether it is shift work, inconvenient work hours, irregular work hours or long work hours participants records 9\%, $11 \%, 2 \%$, and $15 \%$ respectively. Also work exposure whether it is prolonged bending or twisting and standing participants records $20 \%, 17 \%$ respectively. Also exercise performing stress included in this table showing different types of daily activities like walking, climbing, carrying heavy loads and attending gym.

Accordingly maternal muscle activity can be divided as relatively maternal muscle activity counted $37 \%$ of whole participants and strenuous maternal muscle activity which counted $63 \%$ of whole study population $(n=100)$.

The findings of table (4) regarding the mode of delivery which means pregnancy outcome as a result of this study the number of subjects that have been recorded normal easy delivery are $52(n=25)$ out of 100 subjects have been participated in this study (52\%) while number of subjects that recorded normal delivery with augmentation and episiotomy are $30(n=30)$ out of 100 subjects $(30 \%)$ but rate of Cesarean section was only 18 subjects (18\%), so in this study we can notice that the physical activity in general does not increase 
Journal of Environmental Sciences (JES)

Institute of Environmental Studies and Research, Ain Shams University

Fouad, Ghada et al.

the rate of Cesarean section as delivery outcome. Ferreira (2019), conducted a quasi-experimental study involving 255 women divided into two groups: an intervention group engaged in a controlled and supervised exercise program during pregnancy $(n=99)$, and a control group that did not participate in the exercise program. The results showed higher odds of induced labor in the control group when compared with women who underwent the intervention. Which conclude that the implementation of a controlled and supervised exercise program in pregnancy was associated with significantly lower odds of induced deliveries.

Another study by Mirzakhani et al. (2015), showed that performing birth ball exercises for 4-6 weeks at the end of pregnancy could increase the rate of vaginal delivery. El Shamy, Abdelfatah (2017), conducted a study which is a randomized controlled trial that recruited 20 healthy pregnant women aged between 20 and 25 years and able to contract the PFMs. The participants were included in the study at 20 weeks of gestation (WG) and were randomly allocated to one of two groups: the intervention group $(n=10)$ or the control group $(\mathrm{n}=10)$. PFM strength was measured by vaginal squeeze pressure at 20 and 36 WG, and delivery outcomes were evaluated by a blinded searcher from the birth registry after labor. The obtained results showed a significantly higher rate of vaginal delivery in mothers on group performing antenatal PFM exercise compared to the control group. In the Intervention group , 90\% of participants underwent spontaneous vaginal delivery, while this rate in the control group was $0 \%$. 
Journal of Environmental Sciences (JES)

Institute of Environmental Studies and Research, Ain Shams University

Fouad, Ghada et al.

Also Hinman (2015), showed benefits of exercise in pregnancy include reduction in Cesarean section rates, appropriate maternal and fetal weight gain, and managing gestational diabetes. Poyatos-León et al. (2015), who conducted a meta-analysis in (2015) and reported that regular exercise during pregnancy seemed to increase the likelihood of healthy pregnant women achieving a eutocic birth. These all conclusions was corroborated by the present study result, regarding the relatively muscle activity group which shows that the rate of easy vaginal delivery more often than the rate of Cesarean section. This present study shows that moderate maternal physical activity does not endanger the health status of healthy pregnant woman or that of the fetus which in accordance with the conclusions of Petrov, et al. (2015), in whose study the women in exercise group performed a supervised resistance exercise program, twice weekly for 12 weeks (from week 14 to week 25 of gestation), with a moderate to vigorous activity level. However Salvesen et al.(2014) conducted a study with similar characteristics, with a study population of 855 pregnant women who performed aerobic and strength-building exercises from weeks 20 to 36 of their pregnancy. This program consisted of a weekly group session led by a physiotherapist. The women were encouraged to conduct a 45 -minute program at home, at least twice weekly, and to record this activity in a personal training diary. The authors concluded that the performance of physical exercise did not influence the duration of the stages of birth, possibly because the exercise was not 
Journal of Environmental Sciences (JES)

Institute of Environmental Studies and Research, Ain Shams University

Fouad, Ghada et al.

supervised at all times by a professional, and so the correct execution of the procedure could not be evaluated. However this conclusion disagrees with the present study because the correct execution of the procedure could not be evaluated. Emilie et al (2019), have a cohort study among 2,435 nulliparous women with expected uncomplicated delivery, physically active women were less likely to have a complicated delivery than physically inactive women. The results were robust over different levels of physical activity; the higher the level, the lower the odds of emergency C-section (versus any vaginal delivery) and of emergency C-section and vacuum extractor (versus spontaneous delivery). This findings disagree with the present study, maybe because the degree of physical activity used in this study not determined.

Shepherd et al. (2017), Muktabhant et al. (2015), meta-analyses, in which there was no difference in the induction rates between the two groups. Regarding the way of delivery, regular exercise in pregnancy was not associated with a lower cesarean rate, contrary to the results of two recent meta-analyses. . A possible explanation for this finding that disagree with the present study can be that physical activity induces some metabolic and hormonal changes that may affect uterine contractility. Table (5) of association between maternal muscle activity and $2^{\text {nd }}$ stage of labor plus mode of delivery showing a significant difference between both groups of relatively maternal activity and strenuous maternal activity, regarding the $2^{\text {nd }}$ stage of labor: 
- Regarding normal easy delivery, first group of relatively maternal muscle activity recorded 45 subjects $(71.4 \%)$ while second group of strenuous maternal muscle activity recorded 7 subjects (18.9\%).

- Regarding prolonged second stage delivery with augmentation ended with vaginal delivery after episiotomy relatively group recorded 10 subjects (15.9\%) while strenuous group record 20 subjects $(54.1 \%)$.

- Regarding arrest of labor ended by C-section relatively group recorded $8(12.7 \%)$ while strenuous group recorded 10(72\%). P Value $<0.001$ (HS) highly significant.

Blanque (2019), conducted a study through a randomized trial was performed with 140 healthy pregnant women, divided into an exercise group (EG) $(\mathrm{n}=70)$ and a control group $(\mathrm{CG})(\mathrm{n}=70)$. The women who composed the study population were recruited at 12 weeks of gestation. The intervention program, termed SWEP (Study of Water Exercise during Pregnancy) began in week 20 of gestation and ended in week 37. Perinatal outcomes were determined by examining the corresponding partographs, The intervention phase of the study took place from June through October 2016, with the 120 women finally included in EG and CG (60 in each group) which resulted with the women who exercised in water during their pregnancy presented a shorter duration of labor than those who did not. The difference was especially marked with respect to the duration of the first and second stages of labor, which agree with the presen study that moderate or relative maternal exercise 
Journal of Environmental Sciences (JES)

Institute of Environmental Studies and Research, Ain Shams University

Fouad, Ghada et al.

is associated with shorter second stage of labor. The strength of Blanque (2019) study is that large number of participants (140 pregnant women), the high rate of follow up and the fact that exercise program was specially designed for pregnant women. However, Perales et al. (2016), in a study with 166 pregnant women (83 in EG and 83 in CG), with an average age of 31.6 (SD 3.80) years, and who presented an uncomplicated singleton pregnancy, reported that participation in a physical exercise program during pregnancy is associated with a shorter first stage, with no significant differences in the duration of the second and third stages. This contrasts somewhat with the results of the present study, according to which women who perform moderate physical exercise during the second and third trimesters of pregnancy present a significantly shorter second and third stage duration. Also, Szumilewicz et al. (2013), Physical inactivity may also be associated with poor function of the pelvic floor muscles, resulting in insufficient rotational forces and prolonged second stage of labor. This study agrees with our study because our findings show good association between physical activity and decreased duration of second stage of labor.

Goda (2015), conducted A Quasi experimental nonequivalent post-test only research design was used in this study. A convenience sample was utilized, a total of 100 pregnant women. The researcher divided the sample into two groups, the study group constituted (50) women, who received pelvic floor training exercise and the control group constituted (50) women who received the standard routine antenatal care. Findings of this research found 
Journal of Environmental Sciences (JES)

Institute of Environmental Studies and Research, Ain Shams University

Fouad, Ghada et al.

that pelvic floor muscles training exercise during pregnancy showing a statistically significant difference between the two groups related to cervical dilatation $\mathrm{cm} /$ hour, and better labor progress in relation effacement and station. The findings of this research indicated that mothers in the study group revealed better labor progress than those in the control group as related to labor duration. The findings showed that the mean duration of the first, second and third stages of labor were shorter in the study group as compared with the control group. There was statistically significant difference was found between two groups. Similar results were reported by Lixu et al. (2015) , these previous studies also agree with the present study findings that relatively maternal muscle activity showing decrease in mean duration of second and third stages of labor.

Table (8) of association between maternal muscle activity and APGAR score of the baby. There is a significant difference between both groups regarding APGAR scoring system.

- Relatively group showed 3 out of $63(4.8 \%)$ with severely depressed babies versus 2 out of 37 (5.4\%) of strenuous group severely depressed babies.

- Relatively group showed 15 out of 63 (23.8\%) of moderately depressed babies compared with 25 out of 37 (67.6\%) of strenuous group.

- Relatively group showed 45 out of 63 (71.4\%) with excellent condition babies compared to 10 out of $37(27 \%)$ of strenuous group.

P Value $<0$.001 (HS) highly significant. 
Journal of Environmental Sciences (JES)

Institute of Environmental Studies and Research, Ain Shams University

Fouad, Ghada et al.

Ali (2015), a similar study results showed a statistically significant difference in the effect of antenatal exercises in decreasing the intensity of labor pain during the first stage of labor and shortening the first stage of labor in the study group compared with the control group, whereas exercises had no effect on the mode of delivery in both groups. A statistically significant increase in the APGAR scores was found at the critical first and fifth minute after labor, which favored neonates of exercise group than neonates of control group.

However, Ghodsi et al, (2012), conducted a case control study By using a continued method, performed on pregnant women with singleton gestation were assigned to either a training or a control group. The supervised training included three days a week, with duration of 30-45 minutes, from 20-26th weeks until delivery. Neonatal outcomes include neonatal weight and first and fifth minute's APGAR was recorded for two groups. According finding of this study, there were not meaningful statistical evidences for exercise training and first and fifth minute's APGAR or neonatal weight in two groups. This study disagree with the present study maybe due to small size of the sample used in the study. Murtezani et al (2014), conducted a study in which sixty-three nulliparous, previously sedentary, were randomly assigned to either an exercise $(\mathrm{N} .=30)$ or a control $(\mathrm{N} .=33)$ group. The subjects participated in the exercise group (EG) focused on aerobic and strengthconditioning exercise in three sessions for about 20 weeks. We registered the birth weight, birth length, gestational age at time of delivery, Apgar score and 
Journal of Environmental Sciences (JES)

Institute of Environmental Studies and Research, Ain Shams University

Fouad, Ghada et al.

head circumference of the newborn, and there was a significant difference between two groups in Apgar scores at 1 min and 5 min with newborns of the exercise group scoring higher than the control group. No sufficient studies about association of maternal muscle activity with third stage of labor regarding placental separation, so further studies are recommended.

\section{CONCLUSION}

The results of the present study demonstrated that the degree of maternal physical activity affect the mode of delivery and new born outcomes in a sample of 100 female subjects in longitudinal study, suggesting that degree of maternal physical activity should be of primary area of focus when prescribing pregnancy intervention in clinical practice and modification of the pregnant physical activity should be established in order to reach an optimum level of pregnancy and labor outcomes. Further high-quality studies with larger sample sizes are recommended to substantiate these findings.

Results of the present study added additional evidence in the effect of degree of maternal physical activity on pregnancy outcome, mode of delivery and APGAR score ( condition of new born after delivery), it showed that relatively maternal muscle activity were associated with less disturbance of fetal wellbeing and subsequently decreased pregnancy complications and better pregnancy outcome. Despite the fact that the pregnancy is associated with profound anatomic and physiologic changes, exercise has minimal risks 
Journal of Environmental Sciences (JES)

Institute of Environmental Studies and Research, Ain Shams University

Fouad, Ghada et al.

and has been shown to benefit most women. Women with uncomplicated pregnancies should be encouraged to engage physical activity before, during, and after pregnancy. Obstetricians and gynecologists and other obstetric care providers should carefully evaluate women with medical or obstetric complications before making recommendations on physical activity participation during pregnancy. Although the evidence is limited, some benefits to pregnancy outcomes has been shown and there is no evidence of harm when not contraindicated. Physical activity and exercise during pregnancy promotes physical fitness and may prevent excessive gestational weight gain. Exercise may reduce the risk of gestational diabetes, preeclampsia and cesarean deliveries.

Addressing pregnancy related symptoms, increasing exercise intentions and improving quality of life in order to provide clue to the future development of appropriate and effective physical activity interventions for pregnant women on promoting physical activity.

\section{RECOMMENDATIONS}

- Implementation of WHO recommendation on community mobilization through facilitated participatory learning and action cycles with women's groups for maternal and newborn health.

- Implementation of WHO recommendations optimizing health worker roles to improve access to maternal and newborn health interventions.

- Increase access to health workers in remote and rural areas to improve health services during antenatal care. 
- Try to access the family members living with pregnant women to give her support to improve her life style and degree of physical activity to avoid harms on their fetuses and in order to get a healthy newborn.

- Role of media to raise awareness about pregnancy hazards affects mother and newborn as a result of strenuous maternal muscle activity during pregnancy due to poverty and ignorance of some community classes.

- Future studies to be directed towards the investigation of physical activity interventions on both the a forementioned outcomes and the quality of life among pregnant women.

- Contributing further data on whether such interventions can promote the wellbeing of these individuals via the improvements of pregnancy related symptoms.

Additional research is needed to study the effects of exercise on pregnancy and outcomes and to further clarify effective behavioral counselling methods and optimal type, frequency and intensity of exercise. Similar research is needed to improve evidence - based information concerning the effects of occupational physical activity on maternal-fetal health. 


\section{REFERENCES}

Ali G.A; Sayed K.A; Amir G.A ; Kasr Al Ainy medical journal , 2015Kamj.eg.net

Baecke JA, Burema J, Frijters JE. A short questionnaire for the measurement of habitual physical activity in epidemiological studies. Am J Clin Nutr 1982;36(05):936-942

Bonzini et al., 2006; Niedhammer, O’Mahony, Daly, Morrison, \& Kelleher, 2009; Palmer, 2013; Naseriasl et al., 2014)

Bonzini M, Coggon D, Godfrey K, Inskip H, Crozier S, Palmer KT. Occupational physical activities, working hours and outcome of pregnancy: findings from the Southampton Women's Survey. Occup Environ Med 2009;66:685-690.

Elshamy FF, Abdelfattah E, Effect of Antenatal pelvic floor muscle exercise on mode of delivery :A randomized controlled trial. Integr Med Int 2017;4:187-197.

Emilie Nor Nielsen, per kragh Anderson, Hanne Kristine Hegaard Mette Juhl, journal of pregnancy 2017, 2017 Hindawi.com

Ferreia, Cátia Liliana Martins et al. Exercise in Pregnancy: The Impact of an Intervention Program in the Duration of Labor and Mode of Delivery. Rev. Bras. Ginecol. Obstet. [online]. 2019, vol.41, n.2, pp.68-75. ISSN 1806-9339

Ghodsi Z, M Asltoghiri - J Pak Med Assoc,2014-jpma.org.pk

Goda A.A , Fawaz M.A, Ghonem G, Mostafa M.I, Metaweaa H, Effect of Pelvic Floor Muscle Exercise Training Protocol For Pregnant Woman during 3rd Trimester on Labor Duration, Journal of Health, Medicine and Nursing www.iiste.org ISSN 2422-8419 An International Peer-reviewed Journal Vol.15, 2015

Hutchison J 2019, H Mahdy J Hutchison stat pearls [internet] 2019 ncbi.nlm.nih.gov

Jackson RA, Gardeners, Torres LN, HuchkoMJ , Zlatnik MG, Wiliams JC, My obstetricians got me fired; how work notes can harm pregnant patients and what to do about it, obstet, Gynecol 2015, 126; 250A

Juhl M, Strandberg-Larsen K, Larsen PS, Andersen PK, Svendsen SW, Bonde JP, et al. Occupational lifting during pregnancy and risk of 
fetal death in a large national cohort study. Scand J Work Environ Health 2013;39:335-42.

Khojasten , A Arbabisarjou T boryni- global journal of 2016 ncbi.nlm.nih.gov Kjell A Salvesen, Signe N Stafne, Torbjørn M Eggebø, Siv Mørkved 2014 Jan;93(1):73-9. doi: 10.1111/aogs.12260.

Li, Xu., Yihui, Du., Ding, L., Wang, Y., , and Wang, Z., (2015): The effect of antenatal pelvic floor muscle training on labor and delivery outcomes: a systematic review with meta-analysis, International Urogynecology Journal, Springer London, ISSN: 0937-3462 (Print) 1433-3023

Liao 2005 obstet and gynecology clinics of north America 32(2);145-64,vil PubMed

Melzer K, Yschutz, Nsoehnchen American journal of 2010 - Elsevien.

Mirzakhani K, Hejazinia Z, Golmakani N, Sardar MA, Shakeri MT: Effect of performing birth ball exercises during pregnancy on mode of delivery in primiparous women. J Midwifery Reprod Health 2015; 3: 269-275.

Muktabhant B, Lawrie TA, Lumbiganon P, Laopaiboon M. Diet or exercise, or both, for preventing excessive weight gain in pregnancy. Cochrane Database Syst Rev 2015;(06):CD007145 Doi: 10.1002/14651858.CD007145.pub3

Murtezani A, M Pacarada, Ibrami Z, Nevzati A, Nerimane L abazi, The Journal of sports medicine and physical fitness 54(6):802-8 Source - PubMed

Perales et al. (2016) Perales M, Calabria I, Lopez C, Franco E, Coteron J, Barakat R. Regular exercise throughout pregnancy is associated with a shorter first stage of labor. American Journal of Health Promotion. 2016;30(3):149-154. doi: 10.4278/ajhp.140221QUAN-79. [PubMed] [CrossRef] [Google Scholar]

Petrov-Fieril, Glantz \& Fagevik Olsen (2015) Petrov-Fieril K, Glantz A, Fagevik Olsen M. The efficacy of moderate-to-vigorous resistance exercise during pregnancy: a randomized controlled trial. Acta Obstetricia et Gynecologica 
Scandinavica. 2015;94(1):35-42.

doi:

10.1111/aogs.12525. [PubMed] [CrossRef] [Google Scholar]

Poyatos-León et al. (2015) Poyatos-León R, García-Hermoso A, SanabriaMartínez G, Álvarez Bueno C, Sánchez-López M, MartínezVizcaíno V. Effects of exercise during pregnancy on mode of delivery: a meta-analysis. Acta Obstetricia et Gynecologica Scandinavica. 2015;94(10):1039-1047. doi: 10.1111/aogs.12675. [PubMed] [CrossRef] [Google Scholar]

Blanque R. Raquel, Juan-carlos Sanchez-garnia, and maria Jose Aguilar Cordeno Peer J.2019;e6370

Sadeghi B, M Sieraisti-Nir, Z Hajmini,, A Ebadi-Lranian Journal of , 2018ncbi.nim.nih.gov

Salihu, H. M., J. Myers, and E. M. August. "Pregnancy in the workplace." Occupational medicine 62.2 (2012): 88-97.

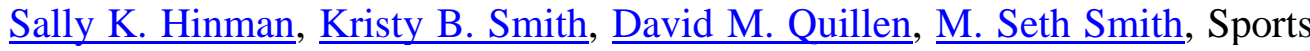
Health. 2015 Nov; 7(6): 527-531. doi: $10.1177 / 1941738115599358$

Salvesen et al. (2014) Salvesen KÅ, Stafne SN, Eggebø TM, Mørkved S. Does regular exercise in pregnancy influence duration of labor? A secondary analysis of a randomized controlled trial. Acta Obstetricia et Gynecologica Scandinavica. 2014;93(1):73-79. doi: 10.1111/aogs.12260. [PubMed] [CrossRef] [Google Scholar]

Shepherd E, Gomersall JC, Tieu J, Han S, Crowther CA, Middleton P. Combined diet and exercise interventions for preventing gestational diabetes mellitus. Cochrane Database Syst Rev 2017;11: CD010443 Doi: 10.1002/14651858.CD010443.pub3

Szumilewicz A, Wojtyła A, Zarębska A, Drobnik-Kozakiewicz I, Sawczyn M, Kwitniewska A: Influence of prenatal physical activity on the course of labour and delivery according to the new Polish standard for perinatal care. Ann Agric Environ Med 2013; 20: 380-389.

ToveS.rosen, David Bateman, In principles of Gender-Specific Medicine(second edition), 2010). 


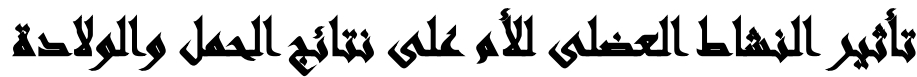

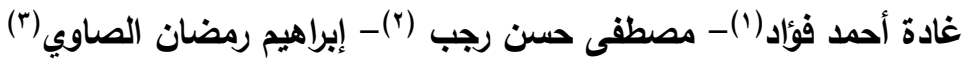

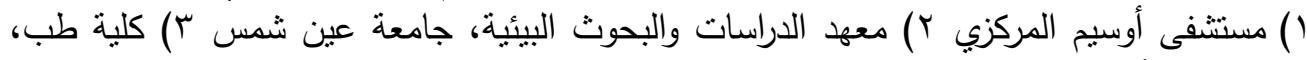 \\ جامعة الأزهر

\section{lil}

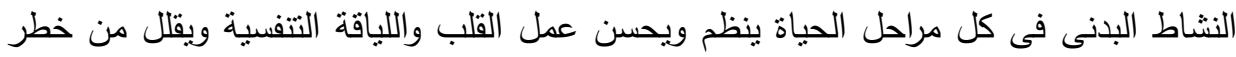

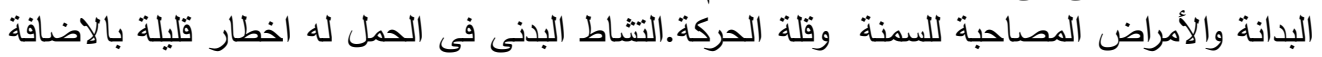

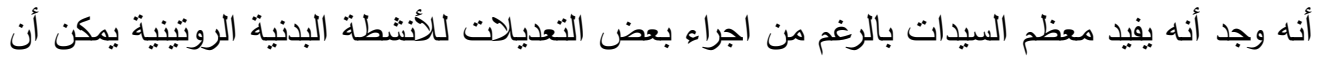

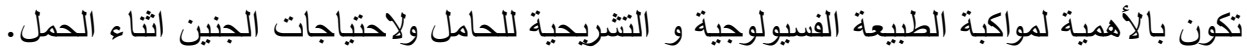

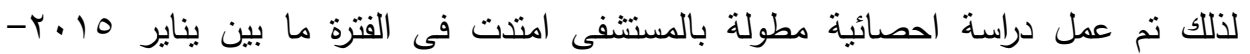

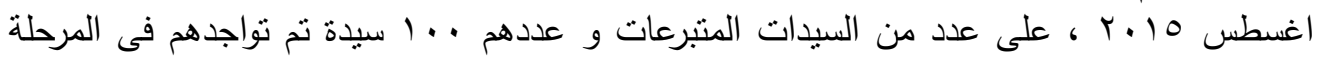

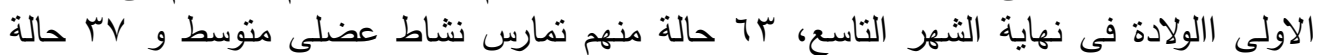

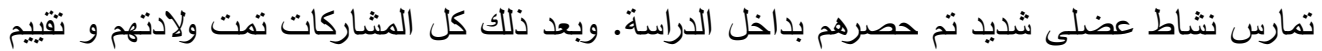
صحة الجنين فى السجلات الطبية.

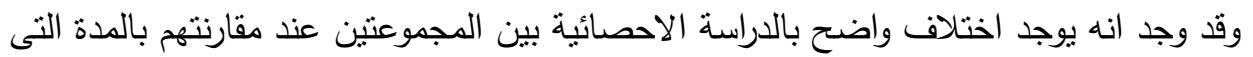

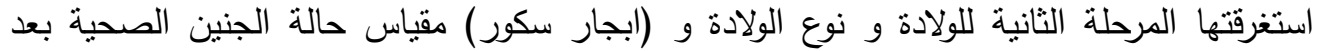

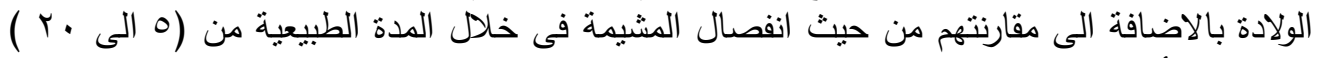

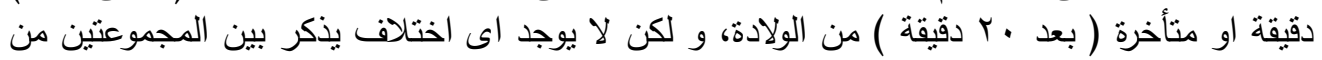

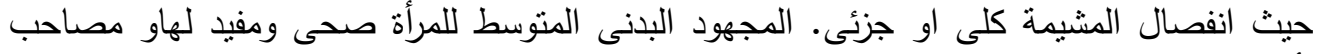

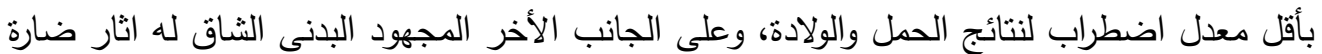



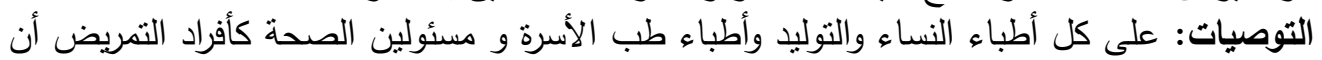

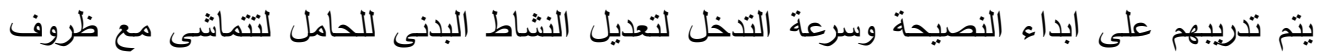

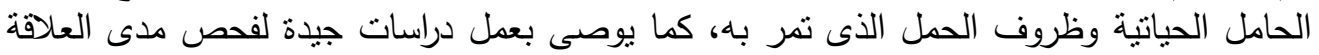

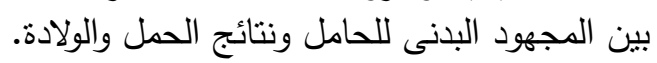
الكلمات الدالة: الدجهود العضلى المنائ المعتل للأم - الحمل - نتائج الولادة. 